\title{
Is there an ideal shunt valve and opening pressure setting for NPH?
}

\author{
Joachim M. K. Oertel ${ }^{1}$ (D) $\cdot$ Matthias J. M. Huelser $^{1}$ \\ Received: 22 September 2020 / Accepted: 24 September 2020 / Published online: 2 October 2020 \\ (C) Springer-Verlag GmbH Austria, part of Springer Nature 2020
}

Which shunt adjustment to select for normal pressure hydrocephalus remains a matter of controversy. While many patients do benefit from medium pressure adjustments, some might need ultralow pressure setting to experience satisfying results. In this issue, an article addressing the difficult adjustment of shunts in normal pressure hydrocephalus patients is presented.

When it comes to the details of shunt valve settings, there is a wide range of options to choose from:

Shall we implant valves regulated by CSF flow or rather use valves regulated by intracranial pressure?

Shall we use a single differential pressure valve or is a combination with an anti-siphon device (ASD) preferable? Shall we opt for valves with a fixed pressure setting or implant valves with an option to adjust the pressure or shall we even implant a combination of fixed pressure valves and adjustable valves?

The application of flow-regulated versus differential pressure-regulated valves in patients with NPH has not been investigated by randomized clinical trials yet [17]. Recently, a study group published two studies about its retrospectively collected data with interesting results concerning outcome and complication rate [14]. Another publication of the same group showed that the use of flow-regulated valves may be comparable with the use of differential pressure valves [15].

It was also demonstrated that the frequency of overdrainage in the flow-regulated group was lower than in the differential

This article is part of the Topical Collection on CSF Circulation

Joachim M. K. Oertel

Joachim.oertel@uks.eu

1 Department of Neurosurgery, Saarland University Medical Center and Saarland University Faculty of Medicine, Homburg,

Saar, Germany pressure valve group. However, it is important to note that no ASD was used, which would have reduced the rate of overdrainage significantly $[2,6,12]$.

Generally, there exists substantial data supporting the fact that when a differential pressure valve is used, it should be done in combination with an ASD, since it has been shown repeatedly that this combination is superior to the stand-alone technique. ASD decreases the rate of overdrainage and does not increase the rate of underdrainage $[2,6,12]$.

In cases where because of cost factors only one valve can be used, existing data suggests that it may be advisable to use only an ASD instead of a differential pressure valve $[5,11]$.

The decision between programmable and fixed devices seemed to be clear - the safety and efficiency of programmable valves have been published in several studies $[5,6,12,16]$.

Having the option to adapt the opening pressure is obviously favorable to treat complications like overdrainage and to optimize the outcome $[4,8,13,16]$.

But even after having made all of these decisions above on what valve to use, the question what is the optimal opening pressure for a patient with NPH still remains - and it is not easy to answer.

Overall, low opening pressures seemed to be favorable for the functional outcome of the NPH patient $[1,3,7,9]$, especially when the shunt system included an ASD for prevention from underdrainage [3, 7]. Furthermore, the stepwise lowering of the opening pressure could possibly be favorable [1, 4]. Therefore, programmable valves in combination with an ASD seems to be the optimal choice.

But there is more. In the following study by Funell et al., a cohort of NPH patients with a low-pressure-state NPH is presented. These patients underwent surgery for replacing a fixed ASD with a programmable ASD (proSA). With this adjustable device, the study group attains a treatment option in this subtype of NPH.

In their conclusion - and the authors of this editorial are in consent with this, they suggest for cases of complex hydrocephalus like the NPH a combination of a programmable differential and anti-gravity valve. 
At present, clinical data about this valve combination are rare. Mansson et al. show the benefit of such a system in complex shunted patients [8]. The recently started SYGRAVA study will evaluate whether programmable anti-siphon devices compared with fixed anti-siphon devices are able to avoid both over- and underdrainage complications [10].

At present, the combination of adjustable differential pressure and adjustable anti-gravity valves is used especially in patients with complex hydrocephalus and CSF-associated diseases when optimum adjustment is needed. In these, it is a very feasible technique. But more data are to come to further refine indication and settings in this subgroup of patients.

\section{References}

1. Delwel EJ, de Jong DA, Dammers R, Kurt E, van den Brink W, Dirven CM (2013) A randomised trial of high and low pressure level settings on an adjustable ventriculoperitoneal shunt valve for idiopathic normal pressure hydrocephalus: results of the Dutch evaluation programme Strata shunt (DEPSS) trial. J Neurol Neurosurg Psychiatry 84:813-817. https://doi.org/10.1136/jnnp2012-302935

2. Freimann FB, Sprung C (2012) Shunting with gravitational valvescan adjustments end the era of revisions for overdrainage-related events?: clinical article. J Neurosurg 117:1197-1204. https://doi. org/10.3171/2012.8.JNS1233

3. Freimann FB, Vajkoczy P, Sprung C (2013) Patients benefit from low-pressure settings enabled by gravitational valves in normal pressure hydrocephalus. Clin Neurol Neurosurg 115:1982-1986. https://doi.org/10.1016/j.clineuro.2013.06.010

4. Golz L, Lemcke J, Meier U (2013) Indications for valve-pressure adjustments of gravitational assisted valves in patients with idiopathic normal pressure hydrocephalus. Surg Neurol Int 4:140. https://doi.org/10.4103/2152-7806.119879

5. Kehler U, Kiefer M, Eymann R, Wagner W, Tschan CA, Langer N, Rohde V, Ludwig HC, Gliemroth J, Meier U, Lemcke J, Thomale UW, Fritsch M, Krauss JK, Mirzayan MJ, Schuhmann M, Huthmann A (2015) PROSAIKA: a prospective multicenter registry with the first programmable gravitational device for hydrocephalus shunting. Clin Neurol Neurosurg 137:132-136. https://doi.org/ 10.1016/j.clineuro.2015.07.002

6. Lemcke J, Meier U, Muller C, Fritsch MJ, Kehler U, Langer N, Kiefer M, Eymann R, Schuhmann MU, Speil A, Weber F, Remenez V, Rohde V, Ludwig HC, Stengel D (2013) Safety and efficacy of gravitational shunt valves in patients with idiopathic normal pressure hydrocephalus: a pragmatic, randomised, open label, multicentre trial (SVASONA). J Neurol Neurosurg Psychiatry 84:850-857. https://doi.org/10.1136/jnnp-2012-303936

7. Malem DN, Shand Smith JD, Toma AK, Sethi H, Kitchen ND, Watkins LD (2015) An investigation into the clinical impacts of lowering shunt opening pressure in idiopathic normal pressure hydrocephalus: a case series. Br J Neurosurg 29:18-22. https://doi. org/10.3109/02688697.2014.950630

8. Mansson PK, Hansen TS, Juhler M (2018) The applicability of fixed and adjustable gravitational shunt valves in two different clinical settings. Acta Neurochir 160:1415-1423. https://doi.org/10. 1007/s00701-018-3568-y

9. Saehle T, Farahmand D, Eide PK, Tisell M, Wikkelso C (2014) A randomized controlled dual-center trial on shunt complications in idiopathic normal-pressure hydrocephalus treated with gradually reduced or "fixed" pressure valve settings. J Neurosurg 121:1257-1263. https://doi.org/10.3171/ 2014.7.JNS14283

10. Scholz R, Lemcke J, Meier U, Stengel D (2018) Efficacy and safety of programmable compared with fixed anti-siphon devices for treating idiopathic normal-pressure hydrocephalus (iNPH) in adults - SYGRAVA: study protocol for a randomized trial. Trials 19:566. https://doi.org/10.1186/s13063-018-2951-6

11. Suchorska B, Kunz M, Schniepp R, Jahn K, Goetz C, Tonn JC, Peraud A (2015) Optimized surgical treatment for normal pressure hydrocephalus: comparison between gravitational and differential pressure valves. Acta Neurochir 157:703-709. https://doi.org/10. 1007/s00701-015-2345-4

12. Toma AK, Tarnaris A, Kitchen ND, Watkins LD (2011) Use of the proGAV shunt valve in normal-pressure hydrocephalus. Neurosurgery 68:245-249. https://doi.org/10.1227/NEU. 0b013e318214a 809

13. Tschan CA, Antes S, Huthmann A, Vulcu S, Oertel J, Wagner W (2014) Overcoming CSF overdrainage with the adjustable gravitational valve proSA. Acta Neurochir 156:767-776; discussion 776. https://doi.org/10.1007/s00701-013-1934-3

14. Wetzel C, Goertz L, Schulte AP, Goldbrunner R, Krischek B (2018) Minimizing overdrainage with flow-regulated valves - initial results of a prospective study on idiopathic normal pressure hydrocephalus. Clin Neurol Neurosurg 173:31-37. https://doi.org/ 10.1016/j.clineuro.2018.07.017

15. Wetzel C, Goertz L, Noe P, von Spreckelsen N, Penner M, Kabbasch C, Goldbrunner R, Krischek B (2020) Flow-regulated versus differential pressure valves for idiopathic normal pressure hydrocephalus: comparison of overdrainage rates and neurological outcome. Acta Neurochir 162:15-21. https://doi.org/10.1007/ s00701-019-04088-9

16. Zemack G, Romner B (2008) Adjustable valves in normal-pressure hydrocephalus: a retrospective study of 218 patients. Neurosurgery 62(Suppl 2):677-687. https://doi.org/10.1227/01.neu.0000316272. 28209.af

17. Ziebell M, Wetterslev J, Tisell M, Gluud C, Juhler M (2013) Flowregulated versus differential pressure-regulated shunt valves for adult patients with normal pressure hydrocephalus. Cochrane Database Syst Rev:CD009706. https://doi.org/10.1002/14651858. CD009706.pub2

Publisher's note Springer Nature remains neutral with regard to jurisdictional claims in published maps and institutional affiliations. 